\title{
Traditional Indonesian Face Masks: Cypirus Rotundus L as a Hyperpigmentation Treatment
}

\author{
Sri Dwiyanti, Siti Sulandjari, Putri Cindy \\ Home Economics Department \\ Universitas Negeri Surabaya, \\ Surabaya, Indonesia \\ sridwiyanti@unesa.ac.id
}

\begin{abstract}
This research focuses on the use of nutgrass plant as a facial treatment to reduce hyperpigmentation. Nutgrass roots, CypirusRotundus $L$, contains flavonoid, an antiinflammatory and antioxidant which are reluctant to radiation reaction. By approaching to experimental method, this research used three formulas based on the different compositions of nutgrass in a face mask namely $10 \%, 20 \%$ and $30 \%$. Findings showed that the third formula which consisted of $30 \%$ nutgrass extract was more effective to reduce hyperpigmentation that other two formulas. It is suggested that nutgrass can be used as a useful ingredient in beauty treatments.
\end{abstract}

Keywords-Cypirusrotundus l; nutgrass roots; face mask hyperpigmentation

\section{INTRODUCTION}

Aging in the form of hyperpigmentation is one skin disorder that occurs in the formation of the amount of melanin pigment forming the color of human skin. [1] facial hyperpigmentation is usually a reflection of an increased amount of melanin either within the epidermis, the dermis, or both (mixed pattern). The increase in melanin content is due to an increased number of functioning melanocytes (melanocytosis), an increased amount of melanin production without a numerical alteration of melanocytes (melanosis), or both.

Melasma is an acquired form of hyperpigmentation that is seen most commonly on the face. It is a common disorder of hyperpigmentation affecting millions worldwide. at least $90 \%$ of those affected are women. The exact pathogenesis is unknown; however, it is hypothesized that rather than an increase in melanocytes, melasma may be caused by the presence of more biologically active melanocytes in the affected skin. [2] Following exposure to UV irradiation, the melanocytes produce increased amounts of melanin compared with uninvolved skin. Exacerbating factors include pregnancy, hormonal therapy, such as oral contraceptives, and intense sun exposure. Sun exposure exacerbates melasma, probably because of the UV-induced upregulation of melanocytestimulating cytokines. Clinically, there are light to dark brown patches with irregular borders most commonly distributed symmetrically on the centrofacial, malar and mandibular regions and can also be on the forearms.
Natural ingredients can be found around us, ranging from fruit, plants and so on, one of the plants that have benefits are the grassroots bulbs. The grass pitcher (the Cyperaceae family), also known as purple nutsdge or nutgrass, is a slender, scaly, scaly, round-shaped, rosebush-shaped weed on the base and a single arise of tubers about 1-3 cm long. Bulbs are externally blackish in color and inside are reddish white, with a distinctive odor. The stems grow about $25 \mathrm{~cm}$ long and the leaves are linear, dark green and fluted on the upper surface. The flowers are small, with 2-4 bracts, consisting of small flowers with red-brown skin. The turquoise grass is native to India, but is now found in the area Tropical, subtropical and moderate [3].

Nut grass have pharmacological and biological properties, namely anti-Candida, anti-inflammatory, anti-diabetic, antidiarrhoeal, cytoprotective, antimutagenic, antimicrobial, antibacterial, antioxidant, cytotoxic and apoptosis, as well as antipyretic analgesics have been reported for the previous phytochemical .Studi plant at grass revealed the presence of alkaloids, flavonoids, tannins, starch, glikosid, and furochromones, and sesquiterpenoids [3]. Flavonoid a good reducing compound, inhibit oxidation reaction, both the enzyme and non enzim. Flavonoid act as a good container radical hydroxide (free radicals) and superoxide (free radicals) thereby protecting the membrane lipids against destructive reactions (Robimsson 1995, in Rahmawati 2008) among other benefits of the berry flavonoids is to protect cell structures, have a synergistic relationship with vitamin $C$ (increase the effectiveness of vitamin C) , Anti-inflammatory, preventing bone loss, and as an antibiotic [4].

Flavonoids are phenolic substances isolated from a wide range of vascular plants, with over 8000 individual compounds known. They act in plants as antioxidants, antimicrobials, photoreceptors, visual attractors, feeding repellants, and for light screening. Many studies have suggested that flavonoids exhibit biological activities, including antiallergenic, antiviral, antiinflammatory, and vasodilating actions. However, most interest has been devoted to the antioxidant activity of flavonoids, which is due to their ability to reduce free radical formation and to scavenge free radicals [5].

The basic ingredients used for traditional masks in general are rice flour. Rice flour is very nutritious, because it contains amylose, amylopectin, hydralized amylum / dekstrin and kojik 
acid that can whiten the skin as a result of amylum fermentation during immersion. Therefore, rice flour is used as one of the basic ingredients of cosmetics, because nutritious can make facial skin become manicured, moisturize the skin and brighten the skin, and has a function as anti oksidan.Selain rice flour serves as a glue, so that when the mask is affixed to the face Can be sticky and cause a sense of tightness.[6]

The research is to make a powder mask that needs a mixture for its use. Bulbs and rice are processed into powders to simplify their use and ketahanlamaannya. Masculine grass mask mask and rice flour using aquades as mixture material. The combination of the two basic ingredients, it can help reduce hyperpigmentation or spots on the face

The purpose of this research is to know the effect of percentage of nut grass on the result so face mask made from rice flour to face condition, wide area of dew, healing time, and face brightness. To know the best masks on facial hyperpigmentation skin care.

\section{METHOD}

This research used experimental method because there is a manipulation variable used in the process of examination. According to Arikunto (2010:9), experimental research is a way to find a causal relationship between two factors that are intentionally being occurred by the researcher through eliminating, reducing, or separating other disrupting factors. This experiment conducted aims to know the effects of different percentages of nutgrass roots' extract and a rice flour on a face skin experiencing hyperpigmentation. The analysis is done by explaining the effects based on several aspects including the skin condition after using the face mask, the size of spots, curing time, and face skin brightness. The population of this research is the women aged 40-45 years old who have face spots. There are three different clusters of sampling; first, 2 persons who used the first composition of face mask $(10 \%$ nutgrass root extract with 5 grams rice flour), 2 persons who used the second composition (20\% nutgrass extract with 5 grams rice flour), and 2 persons who used the third ones ( $30 \%$ nutgrass extract with 5 grams rice flour).

Use volunteer people because C.Rotundus as a traditional uses of natural compounds, especially of plant origin received much attention as they are well tested for their efficacy and generally believed to be safe for human use. [9]

\section{RESULT AND DISSCUSION}

Table I shows that the results of analysis related to the use of face mask based on the skin condition after using the mask, the size of black spots, the color of black spotarea, curing times, and the skin brightness.
TABLE I. THE AVERAGE RESULTS AFTER SEVEN DAYS OF USING THE FACE MASK

\begin{tabular}{|l|c|c|c|c|c|}
\hline & \multicolumn{5}{|c|}{ Results after seven days using the face mask } \\
\cline { 2 - 6 } \multicolumn{1}{|c|}{$\begin{array}{c}\text { Formula } \\
\text { Type }\end{array}$} & $\begin{array}{c}\text { Face Skin } \\
\text { Condition }\end{array}$ & $\begin{array}{c}\text { Size of } \\
\text { Black } \\
\text { Spot } \\
\text { Area }\end{array}$ & $\begin{array}{c}\text { Color } \\
\text { of the } \\
\text { Black } \\
\text { Spot } \\
\text { Aea }\end{array}$ & $\begin{array}{c}\text { Curing } \\
\text { Times }\end{array}$ & $\begin{array}{c}\text { Face Skin } \\
\text { Brightness }\end{array}$ \\
\hline $\begin{array}{l}1 \text { (10\% } \\
\text { nutgrass root } \\
\text { extracts) }\end{array}$ & 2.4 & 2.4667 & 2.7 & 2.6167 & 2.5333 \\
\hline $\begin{array}{l}\text { (20\% } \\
\text { nutgrass root } \\
\text { extracts) }\end{array}$ & 2.8 & 2.35 & 3.2 & 2.7833 & 3.0167 \\
\hline $\begin{array}{l}3 \\
\text { nutgrass root } \\
\text { extract) }\end{array}$ & 3.1 & 3.4833 & 2.65 & 3.3667 & 2.9167 \\
\hline
\end{tabular}

- Face Skin Condition

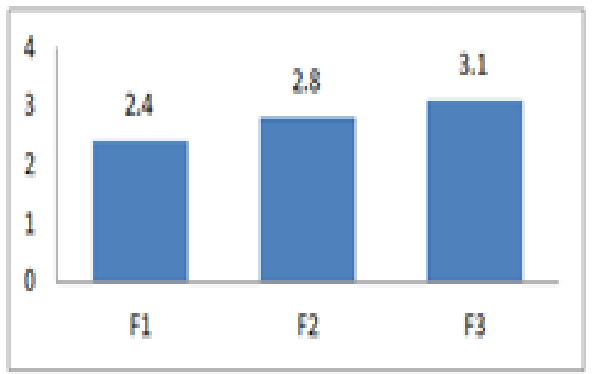

Fig. 1. The average of the face skin condition

Based on Figure 1, the average results of using the face mask on the hyperpigmentation skin shows that the third formula has the highest score for 3.1 categorized as a bit dry, whereas, the first formula has the lowest score for 2.4 categorized as dry. A dry skin type may occur the fast aging, hyperpigmentation, and dull skin. Using a face mask becomes one of the facial treatment to care the face skin condition in order to be healthy, to care face skin problems, so that the face skin can be normalized. In this research, the users of the face mask show that their skin is almost back to normal. Cypirus rotundus as promising herbal drug because of its safety and effectiveness. [7]

\section{1) The Size of Spot Area}

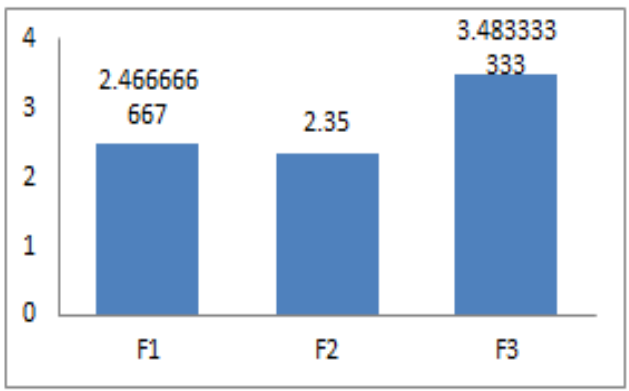

Fig. 2. The average results of the size of spot area 
Based on Figure 2, the average results of using the face mask show that formula 3 has the highest score for 3.4833 which means that the black spot area is still wide, whereas, the lowest one is formula two with 2.35 , meaning that the black spot area is wide but splotchy. The highest total average of the size of black spot is formula 3. The composition used in formula three contains more nutgrass root extract which is good for hyperpigmentation. The nutgrass roots contain flavonoid functioning as an anti-inflammation that can impede cyclooxygenase and lyphooxygenase enzymes to cure any forms of inflammation and allergic [8]. In this case, flavonoid acts as a good receptacle of radical hydroxide and superoxidant, so that, the lipid membrane can be protected from damaging reaction [8].

The assessments about the color of black spot area after using the face mask consist of (4) obscure, (3) cream or nutbrown, (2) brown and (1) blackish-brown. Fig. 4.3 shows that the average result of the use of the face mask on the hyperpigmentation skin is 2.65 (categorized in point 2 namely brown color) up to 3.2 (categorized in point 3 namely nutbrown color), with formula 2 (consisting 20\% nutgrass root extract) as the highest score while formula three (consisting $30 \%$ nutgrass root extract) as the lowest ones.

2) The Color of Area of Black Spots

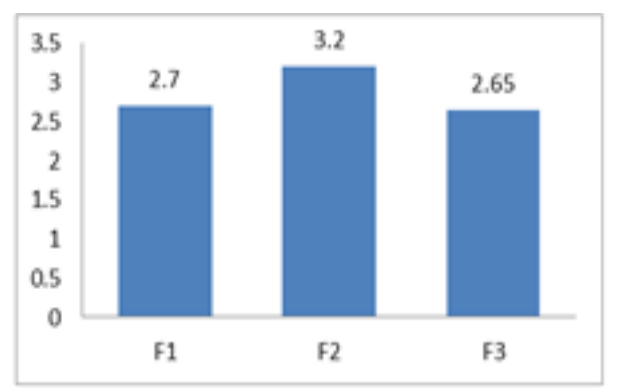

Fig..3. The average result of the color of black spot area

The highest score based on the use of the face mask related to the color changes is formula two. The composition is said to be the best to encounter inflammation as it contains more flavonoid which can impede cyclooxygenase and lyphooxigenase enzymes to cure any form of inflammation and allergic [8]. Moreover, the presence of rice flour is used as antioxidant, to against radical hydroxide and to brighten the skin tone [6].

\section{3) Curing Times}

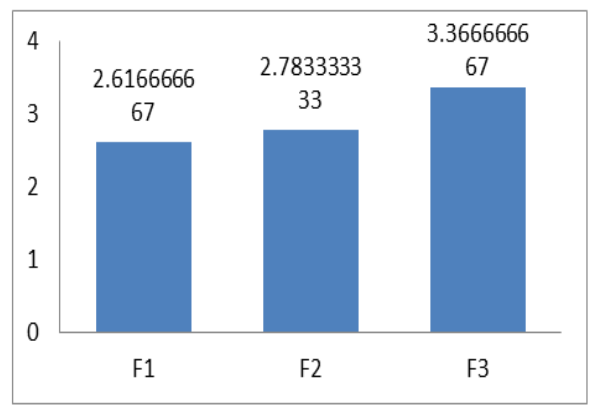

Fig .4. The average scores of curing times
The assessment used to investigate the curing times consists of four points; point 4 is given when the changes happen less than three days, 3 is given for 4 days long, 2 is given for 5 days, and 1 is given when there is no changes at all for couple days ahead. Based on figure 4.4, the average score of the results shown is 2.6167 up to 3.3667 , with the highest score is formula 3 (consisting $30 \%$ of nutgrass root extract). The third formula needs four days to elicit black spots. Another finding shows that formula 1 is the lowest score, meaning that this formula only needs three days to elicit the black spots.

In accordance with this research, the best formula is formula three that only needs less than three days to elicit black spots. The composition is said to be the best to encounter inflammation as it contains more flavonoid which can impede cyclooxygenase and lyphooxigenase enzymes to cure any form of inflammation and allergic. Moreover, flavonoid acts as a receptacle of radical hydroxide and superoxidant to protect lipid membrane from the damage reaction [8].

The assessment of face skin brightness after using the face mask consists of four points; point 1 is for dull skin, 2 is for a bit bright, 3 is for bright, and 4 is for very bright. Based on figure 4.5 , the average score of the results after using the face mask on hyperpigmentation area based on the aspect of face skin brightness is 2.533 up to 3.016. In this case, formula 2 is the highest score, meaning that this formula can make the skin bright. Meanwhile, the lowest score is formula 1, meaning that this formula makes the skin only a bit bright.

\section{4) Face Skin Brightness}

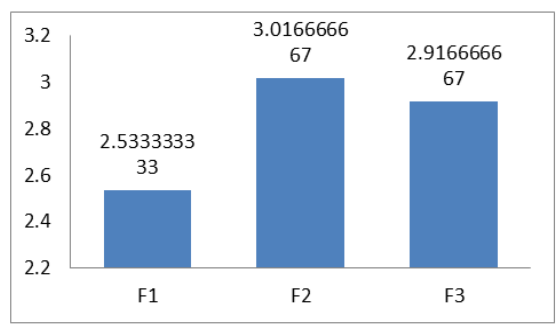

Fig.5. The average score of face skin brightness

Based on the results of the study also known that the best results (3.0: sunny) on the use of masks on facial hyperpigmentation skin for the criteria of the results of facial brightness is the use of formula 2 mask (mixing between the grass $20 \%$ grass and $100 \%$ rice flour) that cause bright results on face. Because rice flour contains antioxidants that serve as an antidote to free radicals and can brighten the skin (Nirmala, 2012). And the natural skin whiteners from plant extracts are more effective, more safe, non-toxic and cost effective when compared with the chemical skin whiteners with diverese side effect. [10]

\section{CONCLUSION}

Based on this research done in seven days, it can be concluded that this traditional face mask made from the combination between nutgrass root extract and rice flour has 
the highest mean in term of the face skin condition after using the mask (showing a bit dry), the size of black spot area (showing a reduce of sizes), the color of the area of the spots (showing brown color), the curing time (showing 3 days of curing time), and the skin brightness (showing a bright skin) using the third formula (30\% nutgrass root extract and 5 grams rice flour). Another interesting finding is the third formula is the best composition in curing hyperpigmentation as the more flavonoid used, the better the results. This is due to that flavonoid functions as anti-inflammation and a good reducing substance for obstructing oxidation reaction, either for enzyme or non-enzyme.

\section{ACKNOWLEDGEMENT}

Special Gratitude and Appreciation to :Rector Unesa Prof. Drs Warsono, M.Pd, who give chance to us to develop our knowledge, Head of The Institute for Research and Community Service Unesa Prof. Dr. Lies AminLestari who entrusting us to hold this research., Dean of Technique Faculty, Prof . Dr. Ekohariyadi, M.Pd. who supporting us to do this research, Head of Department PKK Unesa Dr.Rita Ismawati, M.Kes., All Academicians of Unesa.

\section{REFERENCES}

[1] Jimbow, kowichi. Yasushi Minamitsu. Topical Therapies for Melasma and Disordes of Hyperpigmentation. Dermatologic Therapi. Vol.14, Issue 1. 2001

[2] Sheth VM, Pandva AG. Melasma: a comprehensive update: part I. J Am Acad Dermatol 2011; 65:689-97; quiz 698.

[3] Lawal, O. A. dan Adebola, O. 2009. "Chemical Composition Of The Essential Oils Of Cyperus Rotundus L. From South Africa”.Journal Molecules 2009, 14, 2909-2917.

[4] Barnes, M.A., M. Patricia., Powell-Griner. E. 2004. "Complementary and Alternative Medicine Use Among Adult". United States. 1-2 (jurnal).

[5] Nirmala. 2002. “Khasiat Dibalik Bedak Dingin”. Diakses http://badbadgalz.blogspot.com/2010/08/lulur-tradisional-lulurkunyit-tepung.htm,2002

[6] Ali Esmail Al-Snafi.2016. A Review On Cyperus Rotundus A Potential Plant. IOSR JournalOf Pharmacy. Volume 6, Issue 7 Version

[7] Robinson, Trevor. 1995. “Kandungan Organik Tumbuhan Tinggi. Bandung”. ITB.p 74-174

[8] Ranjani, sivalan. 2013. Medicinal uses and pharmacological activities of Cyperus Rotundus Linn. International Journal Of Scientific and Research Publication, vol.3,Issue 5.

[9] Jennifer, C., Stephie, CM., Abbhishri, S.B., and Shalini B., 2012. A Review On Skin Whitening Property Of Plant Extract. International Journal Of Pharma and Bio Science 